\title{
The electromyographic silent period produced by supramaximal electrical stimulation in normal man
}

\author{
D. L. MCLELLAN ${ }^{1}$ \\ From the University Department of Neurology, Institute of Neurological Sciences, \\ Southern General Hospital, Glasgow
}

SUMMARY The electromyographic silent period produced by supramaximal electrical stimulation of the median nerve was recorded in the abductor pollicis brevis muscle of four normal subjects during maximal isometric voluntary contraction. Except for an inconstant $F$ response, electrical silence could usually be induced in the muscle from the twitch potential until the reappearance of uninterrupted voluntary activity. The silent period produced by stimulation at the wrist was approximately $25 \mathrm{msec}$ longer than that produced by stimulation at the elbow and was independent of muscle tension. Further shortening of the muscle during the twitch contraction did not significantly alter the length of the silent period. A silent period in the abductor pollicis brevis muscle was also obtained after stimulation of the ulnar nerve, at the wrist and at the elbow. The onset of this period of silence was delayed, but it ended at the same time after the stimulus as the corresponding silent periods produced by median nerve stimulation. It is concluded that the end point of the silen period produced by supramaximal electrical stimulation of a mixed peripheral nerve is determine

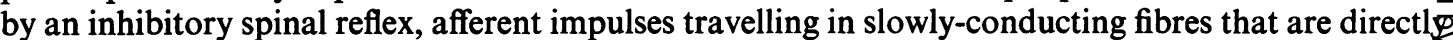
activated by the stimulus. Under these conditions the length of the silent period gives no indication of spindle activity in the muscle.

The electromyographic silent period (Merton, 1951) following electrical stimulation of the nerve to an actively contracting muscle is the resultant of several effects of the stimulus. It has been shown that the early part of the silent period is produced by antidromic impulses passing up the motor fibres (Merton, 1951; Herman, 1969). There has been general acceptance of the view that the end point of the silent period is determined by re-extension of the muscle spindles after the twitch contraction (Higgins and Lieberman, 1968a, b). The occurrence of normal silent periods in patients with the rigidity of Parkinsonism, for example, has been interpreted as evidence of normal gamma motor neurone activity in rigidity (Dietrichson, 1971; Higgins, Haidri and Wilbourn, 1971). However, voluntary activity is not dependent upon the presence of feed-

1 Present address and requests for reprints: Department of Neurology, Section of Neurological Sciences, The London Hospital, London E1 1BB. back signals from muscle spindles: a deafferented muscle can develop good voluntary contraction and the cessation of afferent impulses from spindles would not be expected to interrupt maximal voluntary contraction completely. The situation is different in the decerebrate cat, where tonic alpha motor neurone activity results mainly from a central drive on the gamma motoneurones; in such a preparation unloading of the spindles would necessarily terminate the activation of alpha motoneurones. In normal voluntary activity it is likely that alpha motoneurones are activated directly through the pyramidal system and indirectly via the gamma system, both systems working concurrently to produce contraction (Matthews, 1964; Vallbo, 1970). Direct alpha motoneurone activation is likely to be of particular importance in maximal isometric voluntary contraction, in which the amount of alpha motoneurone activity is not primarily determined by changes in muscle 
length. The purpose of the present study was to establish whether the end point of the silent period under these conditions is determined by direct stimulation of sensory nerve fibres or by activation of muscle receptors.

\section{METHOD}

Four normal male volunteers, aged between 23 and 31 years, were studied. After preparation of the skin with standard electrode jelly, skin-clip surface electrodes were placed $3 \mathrm{~cm}$ apart over the abductor pollicis brevis muscle. Stimulating electrodes $3 \mathrm{~cm}$ apart with the cathode distal to the anode were placed over the ulnar nerve at the lower end of the forearm and at the elbow, and the distance between the two sites of stimulation was measured. The subject was comfortably seated and the right upper limb was placed in a frame that held clamps for the hand and forearm. The palm of the hand was clamped between a vertical wooden plate and a wooden elliptical disc (diameters $15 \times 7 \mathrm{~cm}$ ) that could be screwed towards the plate from its mounting on the frame. The forearm was held in a stiff polyethylene sleeve from wrist to elbow; the sleeve was screwed to the frame and its diameter could be adjusted by inelastic tapes so that the forearm was held securely. The wrist and forearm were held in the neutral position while the elbow was semi-flexed.

An isometric tension transducer (Devices type
4150) was attached to the proximal phalanx of the thumb by steel wire. The transducer was modified by a mechanical fulcrum to give an extended range of up to $6 \mathrm{~N}$; the force applied during maximum contraction varied between subjects but was approximately $2.5 \mathrm{~N}$. The circuit plan is shown in Fig. 1. The output from the transducer was fed through a Devices Transducer Function Unit (type 3559) and A.C. coupled to one channel of a storage oscilloscope (Tektronix RM 564) with a frequency response of $0 \cdot 1-10^{4} \mathrm{~Hz}$. The output from the surface electrodes was fed into a Devices A.C. High Gain Function Unit (type 3542), and the output was displayed on the second channel of the storage oscilloscope.

A data retrieval computer (Nuclear Chicago, type 7100), operating in the transient averaging mode, was used to average the data from 10 consecutive recordings. The purpose of the computer was partly to check the accuracy of the mean silent period values and partly to provide an averaged record that could confirm that individual traces were representative of a consistent and reproducible phenomenon. This computer can analyse unrectified signals only when they occur at the same point along the time base of a computer; random signals such as EMG signals would average to zero because of subtraction of negative from positive potentials over the course of several sweeps. The EMG signal from the high gain function unit was, therefore, full wave rectified with no smoothing, the frequency response of the

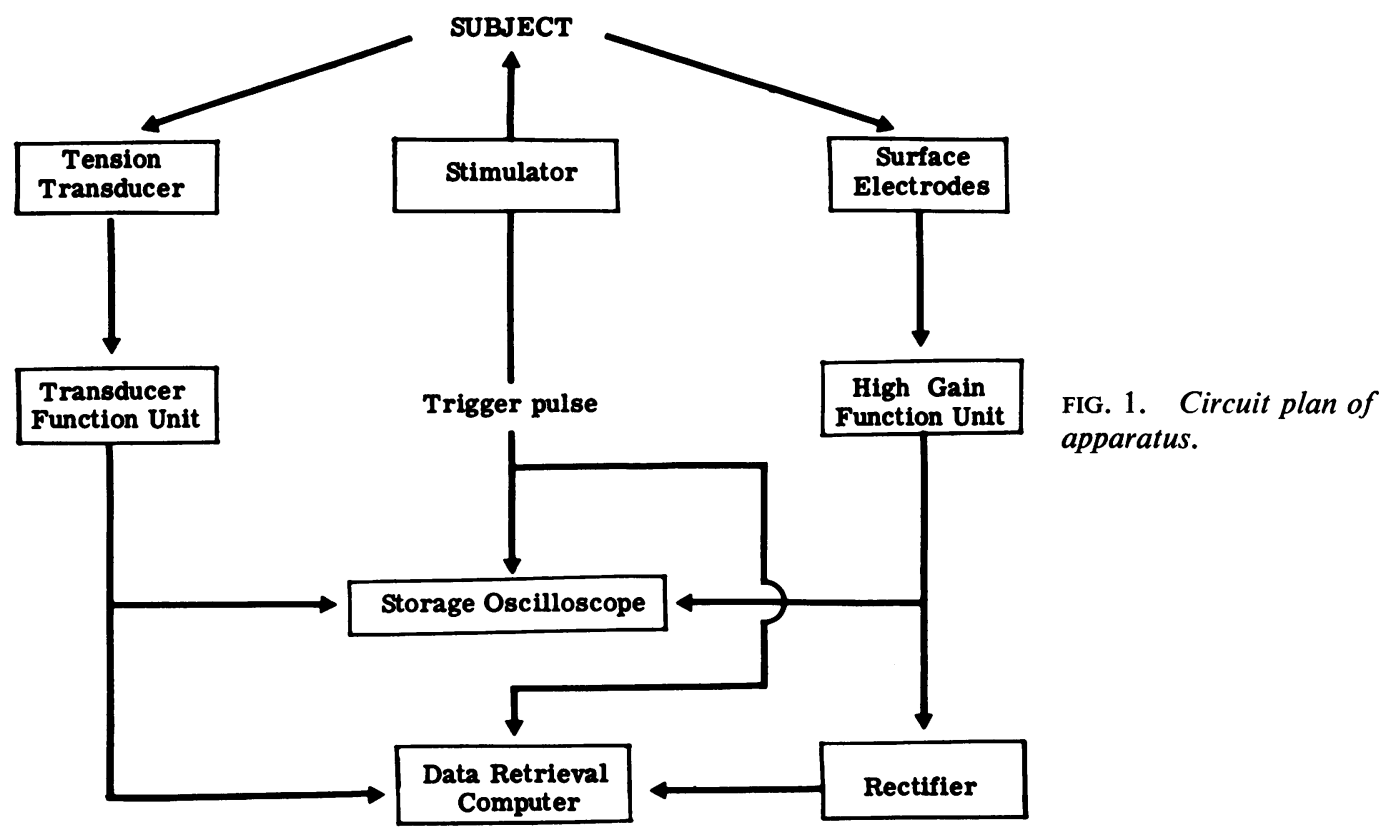


computer being $0 \cdot 1-10^{7} \mathrm{~Hz}$. In this way, time-locked periods of silence could clearly be identified. In some computer records the EMG base line shifted slightly during the silent period and it was not possible to detect from the record alone whether the shift was caused by slight EMG activity or by movement artefact during the silent period. Analysis of individual unrectified records (using the storage oscilloscope) confirmed that the end point of the silent period was not obscured by artefact. When the computer was in operation, a second channel was used to average the output from the transducer function unit.

The subject maintained maximal isometric abduction of the thumb against the transducer, the steadiness of the applied force being monitored by the subject and by the observer using the trace location device on the oscilloscope. A supramaximal stimulus was delivered from a Disa stimulator (type 14E11) which triggered the oscilloscope or the computer. A square wave electrical stimulus of $400 \mathrm{~V}$ lasting $0 \cdot 2$ msec was applied to the median nerve first at the wrist and then at the elbow. Further measurements of the silent period were made using the same stimulus superimposed upon moderate voluntary contraction; after a series of such readings the steel wire between the thumb and the tension transducer was replaced by an elastic band and further identical stimuli were superimposed upon a moderate voluntary contraction. The steel wire was then returned and the stimulating electrodes were moved to overlie the ulnar nerve at the wrist and at the elbow; the distance between the two sites of stimulation was measured. A stimulus of the same intensity was delivered to the ulnar nerve, first at the wrist and then at the elbow, while the subject maintained maximal abduction of the thumb as before. The electromyographic activity in the abductor pollicis brevis muscle and the output from the tension transducer were displayed first on the storage oscilloscope and photo-

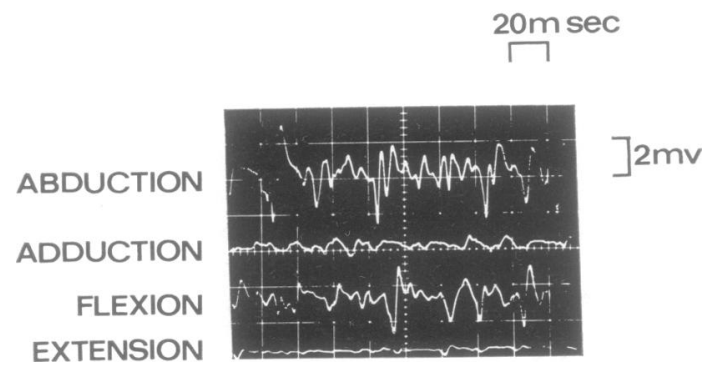

FIG. 2. Electromyograms from surface electrodes over the abductor pollicis brevis muscle during attempts by subject to move the thumb against resistance in the directions shown. For discussion see text. graphed, enabling the changes in tension and electromyographic activity after successive stimuli to be compared. Series of 10 consecutive recordings were then averaged by the computer; the averaged traces were displayed on the storage tube of the computer and photographed. The length of the silent period was taken as the interval between the stimulus and the onset of uninterrupted voluntary activity, or the S-X interval (Higgins and Lieberman, 1968a).

To confirm that the recording electrodes were correctly positioned, the electromyographic activity occurring during abduction, adduction, flexion, and extension of the thumb against resistance was recorded. A typical record is shown in Fig. 2, from which it is clear that nearly all the recorded activity arose from the abductor and flexor pollicis brevis muscles. With surface electrodes it is not possible to record selectively from only one of these muscles and it is doubtful whether they can be selectively contracted by a normal subject, particularly during maximum effort. Fig. 2 also shows that interference from the adductor pollicis brevis muscle (supplied by the ulnar nerve) could not have obscured or mimicked the activity obtained from the abductor pollicis brevis muscle during the recordings.

\section{RESULTS}

The silent period (S-X interval, Fig. 3) produced by supramaximal stimulation of the median nerve at the wrist during maximal isometrices contraction was reasonably constant for each subject; the intra-individual variation can be seen in Table 1, which shows the full data obtained from the four subjects (numbered 1-4) during series of 10 consecutive stimulations. The mean length of the silent period for the four subjects was approximately $103 \mathrm{msec}$, with a range of 96 to $113 \mathrm{msec}$. When the strength of the basal contraction was reduced or the thumb allowed to move during the twitch contraction, the silent period altered by less than $3 \mathrm{msec}$ in three of the subjects, though the fourth showed prolongation of his silent period by $8 \mathrm{msec}$ during isotonic basal contraction (Table 1, Figs 3 and 4). In all subjects, the silent period produced by stimulation at the elbow ended earlier than the silent period produced by stimulation at the wrist, the mean difference being approximately $25 \mathrm{msec}$. Stimulation of the median nerve usually produced silence in the muscle immediately after the twitch response and this silence continued, except for the inconstant $F$ response and occa- 

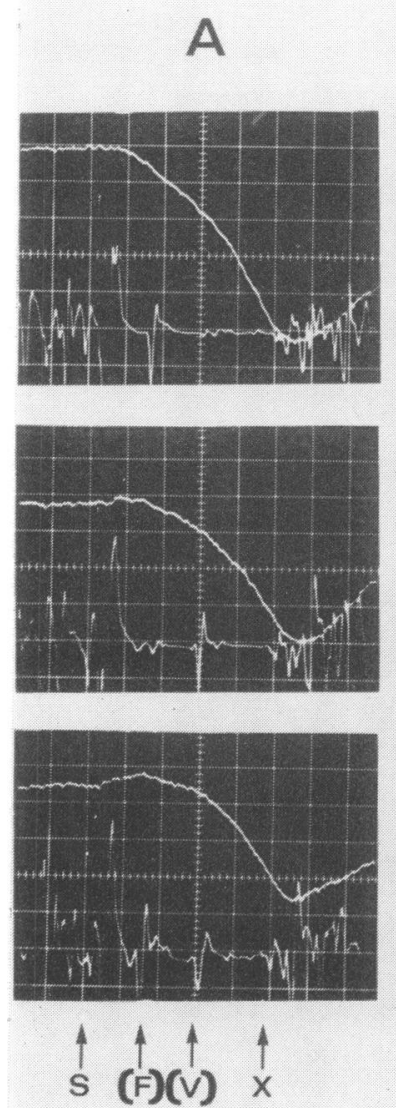
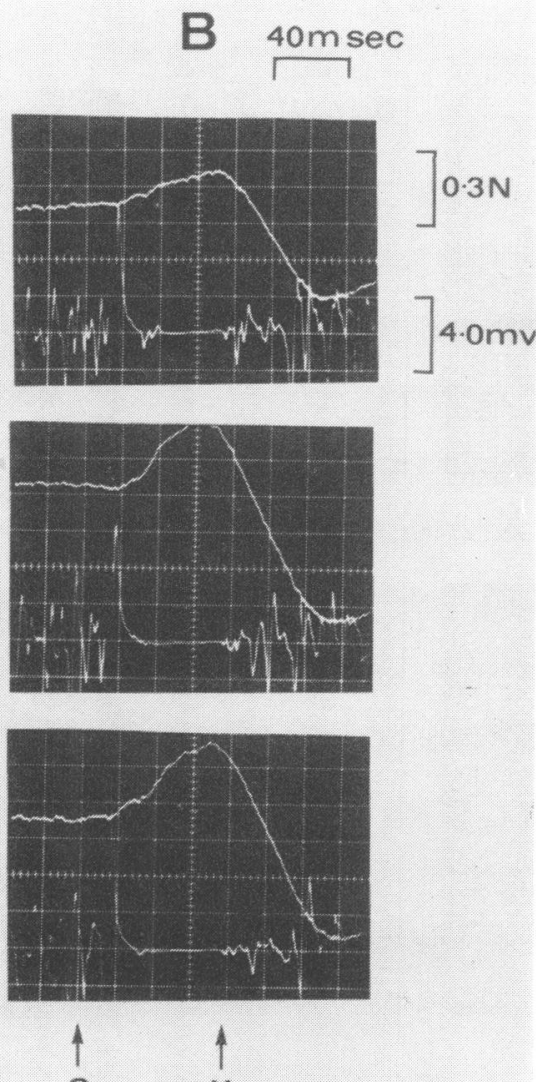

s
FIG. 3. Individual records from the same subject showing effect of stimulation of the median nerve at the wrist (A) and elbow (B) during maximal isometric contraction of the abductor pollicis brevis muscle. Tension (upper traces) and surface electromyogram (lower traces). Stimulus applied at $\mathbf{S}$. $F$ wave at F. Occasional breakthrough voluntary activity at V. Silent period ends at X. The S-X interval is independent of tension changes occurring after the stimulus but is shorter after stimulation at the elbow.

TABLE 1

SILENT PERIODS RECORDED AFTER STIMULATION OF THE MEDIAN NERVE

\begin{tabular}{|c|c|c|c|c|c|c|c|c|c|c|c|c|c|c|c|c|}
\hline \multirow{3}{*}{$\begin{array}{c}\text { Basal contraction } \\
\text { Site of stimulation } \\
\text { Subject }\end{array}$} & \multicolumn{8}{|c|}{ Maximal isometric } & \multicolumn{4}{|c|}{ Moderate isometric } & \multicolumn{4}{|c|}{ Moderate isotonic } \\
\hline & \multicolumn{4}{|c|}{ Wrist } & \multicolumn{4}{|c|}{ Elbow } & \multicolumn{4}{|c|}{ Wrist } & \multicolumn{4}{|c|}{ Wrist } \\
\hline & 1 & 2 & 3 & 4 & 1 & 2 & 3 & 4 & 1 & 2 & 3 & 4 & 1 & 2 & 3 & 4 \\
\hline $\begin{array}{l}\text { Silent periods (S-X } \\
\text { intervals, msec) }\end{array}$ & $\begin{array}{l}116 \\
110 \\
112 \\
110 \\
114 \\
110 \\
112 \\
118 \\
120 \\
108\end{array}$ & $\begin{array}{r}98 \\
96 \\
94 \\
94 \\
94 \\
96 \\
94 \\
98 \\
98 \\
100\end{array}$ & $\begin{array}{l}108 \\
104 \\
108 \\
108 \\
100 \\
104 \\
102 \\
100 \\
104 \\
100\end{array}$ & $\begin{array}{r}96 \\
100 \\
94 \\
96 \\
104 \\
100 \\
98 \\
98 \\
94 \\
96\end{array}$ & $\begin{array}{r}96 \\
96 \\
96 \\
94 \\
102 \\
94 \\
104 \\
94 \\
92 \\
94\end{array}$ & $\begin{array}{l}88 \\
84 \\
80 \\
88 \\
78 \\
78 \\
78 \\
78 \\
84 \\
78\end{array}$ & $\begin{array}{l}64 \\
56 \\
56 \\
56 \\
64 \\
60 \\
54 \\
60 \\
54 \\
54\end{array}$ & $\begin{array}{l}76 \\
74 \\
78 \\
74 \\
70 \\
74 \\
76 \\
78 \\
74 \\
70\end{array}$ & $\begin{array}{l}116 \\
122 \\
118 \\
116 \\
108 \\
116 \\
112 \\
110 \\
112 \\
116\end{array}$ & $\begin{array}{r}98 \\
98 \\
110 \\
90 \\
100 \\
96 \\
96 \\
100 \\
98 \\
96\end{array}$ & $\begin{array}{r}98 \\
98 \\
106 \\
102 \\
108 \\
100 \\
108 \\
108 \\
106 \\
102\end{array}$ & $\begin{array}{r}100 \\
100 \\
110 \\
104 \\
100 \\
94 \\
106 \\
106 \\
106 \\
96\end{array}$ & $\begin{array}{l}106 \\
118 \\
122 \\
118 \\
110 \\
116 \\
108 \\
106 \\
116 \\
114\end{array}$ & $\begin{array}{r}98 \\
96 \\
96 \\
96 \\
106 \\
100 \\
100 \\
100 \\
96 \\
102\end{array}$ & $\begin{array}{l}108 \\
112 \\
106 \\
106 \\
100 \\
100 \\
108 \\
100 \\
110 \\
104\end{array}$ & $\begin{array}{l}108 \\
106 \\
114 \\
116 \\
108 \\
108 \\
106 \\
112 \\
112 \\
116\end{array}$ \\
\hline Individual means (msec) & $113 \cdot 0$ & $96 \cdot 0$ & $103 \cdot 8$ & $97 \cdot 6$ & $96 \cdot 2$ & $81 \cdot 4$ & $57 \cdot 8$ & $74 \cdot 4$ & $114 \cdot 6$ & $98 \cdot 2$ & $104 \cdot 6$ & $102 \cdot 2$ & $113 \cdot 4$ & $99 \cdot 0$ & $105 \cdot 4$ & $110 \cdot 6$ \\
\hline Mean for group (msec) & \multicolumn{4}{|c|}{$102 \cdot 6$} & \multicolumn{4}{|c|}{$77 \cdot 5$} & \multicolumn{4}{|c|}{$104 \cdot 9$} & \multicolumn{4}{|c|}{$107 \cdot 1$} \\
\hline
\end{tabular}



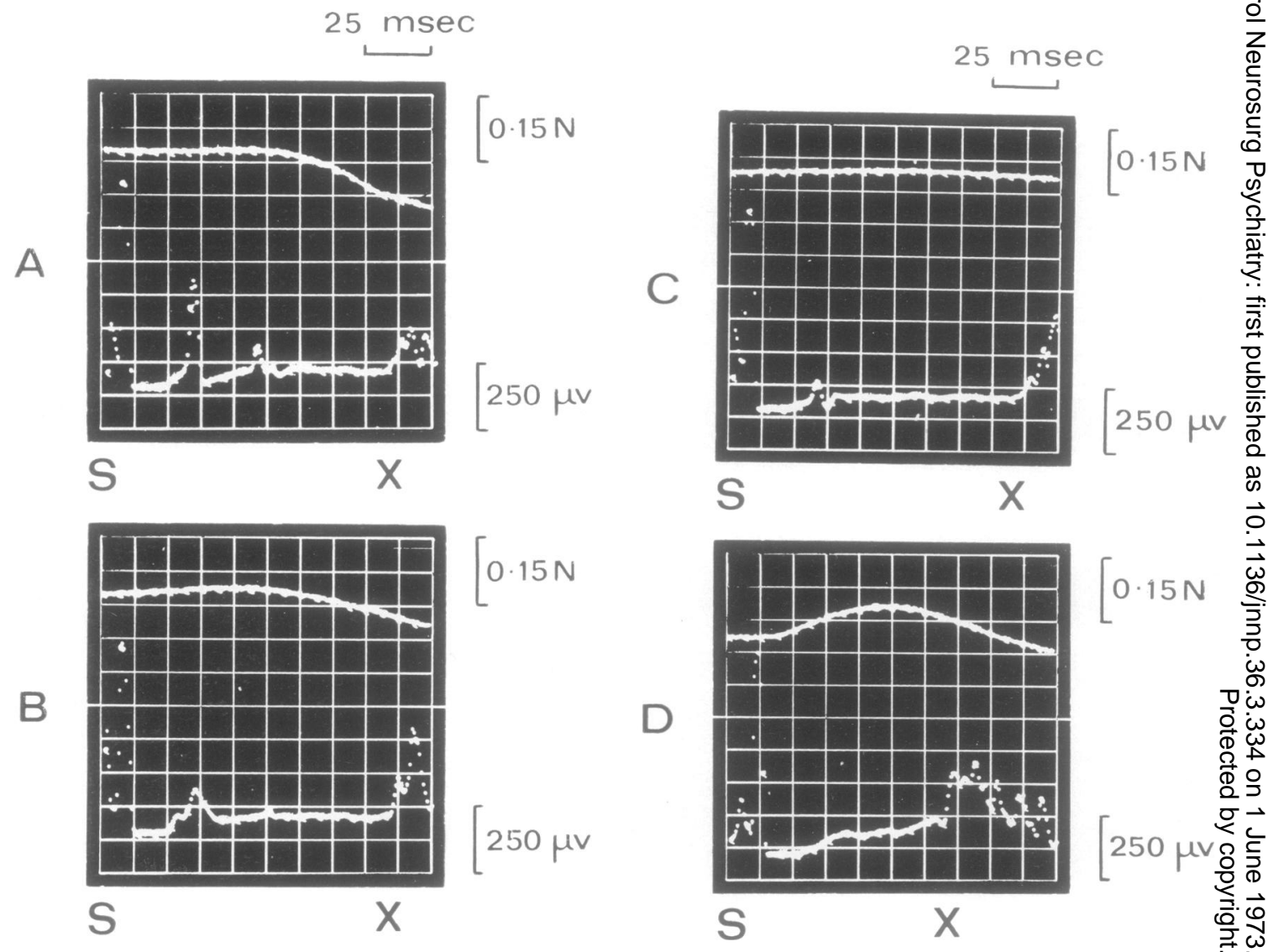

FIG. 4. Effect of stimulation of the median nerve at the wrist during maximal isometric contraction. A, moderate isometric contraction $\mathrm{B}$ and moderate contraction against an elastic resistance $\mathrm{C}$; effect of stimulation at the elbow during maximal isometric contraction D. Tension (upper trace in each figure) and electromyogram (lower trace): averaged effect of 10 stimulations, with standard calibration in all figures. Stimulus applied at S. Silent period ends at X. The S-X interval is independent of the nature of the contraction at the time of the stimulus (A, B, C) but is shorter after stimulation at the elbow (D).

sional breakthrough voluntary activity, until the onset of uninterrupted voluntary activity. The presence of $F$ or of breakthrough activity did not appear to alter the end point of the silent period in this series of observations (Fig. 3).

Stimulation of the ulnar nerve, which does not normally supply the abductor pollicis brevis muscle, also produced a silent period in the muscle. The full data are given in Table 2. The onset of this electrical silence (designated ' $O$ ') was delayed for about $65 \mathrm{msec}$ after delivery of the stimulus at the wrist; the onset of this silent period occurred approximately $18 \mathrm{msec}$ earlier when the ulnar nerve was stimulated at the elbow than when it was stimulated at the wrist, while the end point occurred approximately $21 \mathrm{msec}$ earlier. Although the hand was clamped as firmly as possible and maximal isometric contraction was attempted, slight movement of the hand could not be avoided because of the nature of the soft tissues. Movement during the twitch contraction was noticeable after stimulation at the elbow because of the other muscles activated by stimulation there; this movement was responsible for the difference between tension changes recorded after stimulation at the wrist and those 
TABLE 2

SILENT PERIODS RECORDED AFTER STIMULATION OF ULNAR NERVE DURING MAXIMAL ISOMETRIC CONTRACTION

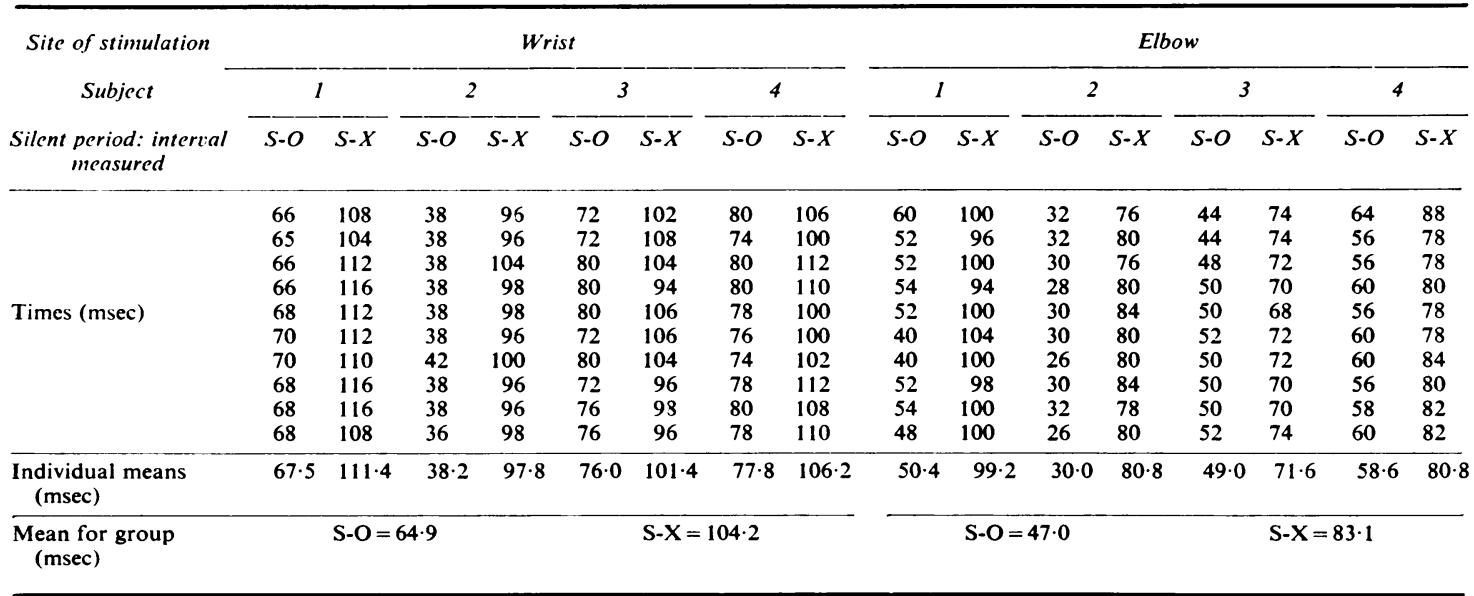

S-O: time between stimulus and onset of silent period. S-X: time between stimulus and end of silent period.

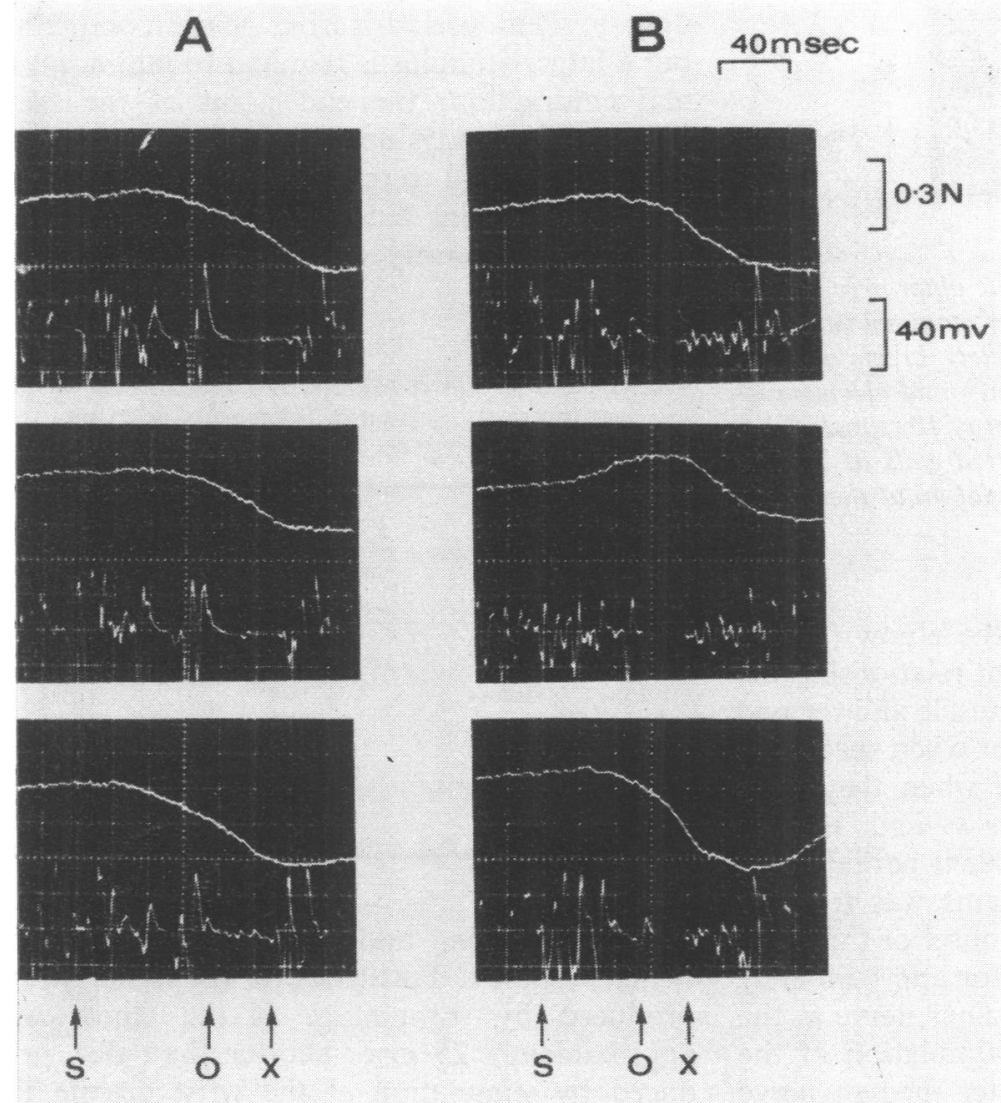

FIG. 5. Individual records from the same subject showing effect of stimulation of the ulnar nerve at the wrist (A) and elbow (B) during maximum isometric contraction of the abductor pollicis brevis muscle. Tension (upper traces) and surface electromyogram (lower traces). Stimulus applied at $\mathrm{S}$. Period of silence begins at $\mathrm{O}$ and ends at X. Both the $\mathrm{S}-\mathrm{O}$ and $\mathrm{S}-\mathrm{X}$ intervals are shorter after stimulation at the elbow. 


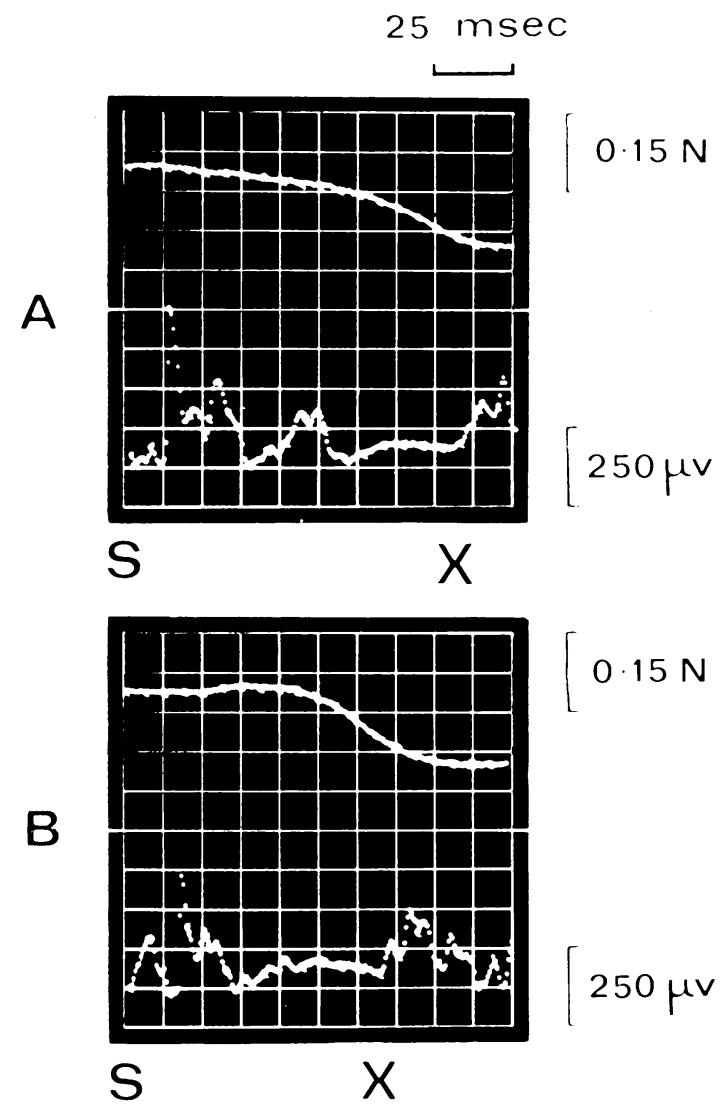

FIG. 6. Effect of stimulation of the ulnar nerve at the wrist $\mathrm{A}$, and at the elbow $\mathrm{B}$, during maximal isometric contraction of the abductor pollicis brevis muscle. Tension (upper trace in each figure) and electromyogram (lower trace): averaged effect of 10 stimulations. Stimulus applied at $\mathrm{S}$. Silent period ends at X. The S-X intertal is shorter after stimulation at the elbow.

recorded after stimulation at the elbow (Figs 5 and 6). There was no consistent relationship between tension changes in the muscle and the end point of the silent period, either when successive recordings were compared or when they were averaged. Stimulation of ulnar and median nerves at the wrist produced silent periods with similar end points, and the same was true for stimulation at the elbow. The onset of the silent period, however, was delayed for approximately $65 \mathrm{msec}$ after stimulating the ulnar nerve at the wrist and for $47 \mathrm{msec}$ after stimulation of the ulnar nerve at the elbow. After median nerve stimulation, the first part of the silent period (immediately after the twitch response) presumably resulted from an antidromic volley that would be produced in the motor neurones supplying the abductor pollicis brevis muscle by direct stimulation of the median nerve but not by stimulation of the ulnar nerve.

\section{DISCUSSION}

These findings indicate that the length of the muscle silent period ( $\mathrm{S}-\mathrm{X}$ interval) after supramaximal stimulation of a mixed peripheral nerve is not related to activation of spindle receptors by changes in muscle length or to activation of Golgi tension receptors. The observations confirm previous reports that the end point of the silent period is consistent for an individual whether the contraction is isometric or isotonic, and is independent of the twitch amplitude (Higgins and Lieberman, 1968a, b; Dietrichson, 1971; Higgins et al., 1971). A small stimulus can pro히 duce a silent period during gentle contractiof but a larger stimulus is required to inhibit maxio + mal contraction; the end point of the silen⿷ period, however, is normally constant and can $\vec{c} \vec{c}$ not be attributed to the activation of spindle re $\varrho \frac{0}{5}$ ceptors or Golgi tendon organs, because the timing and intensity of such activation wouls

TABLE 3

SHORTENING OF SILENT PERIODS PROIDUCED BY PROXIMAI STIMULATION, SHOWING IMPLIED CONIDUCTION VELOCITY OF AFFERENT IMPULSE

\begin{tabular}{|c|c|c|c|}
\hline Subject & $\begin{array}{c}\text { Verte } \\
\text { stimulated }\end{array}$ & $\begin{array}{c}\text { Differences between } \\
\text { S-X interval obtained } \\
\text { at wrist and sllbow } \\
(\text { msec) }\end{array}$ & $\begin{array}{l}\text { Conduction } \\
\text { relocity } \\
\text { (msec) }\end{array}$ \\
\hline & & & $\ldots$ \\
\hline \multirow[t]{2}{*}{1} & Median & $17 \cdot 2$ & 14.0 \\
\hline & Ulnar & $12 \cdot 2$ & $21 \cdot 3$ \\
\hline \multirow[t]{2}{*}{2} & Median & 14.6 & 15.6 \\
\hline & Ulnar & $17 \cdot 0$ & 15.4 \\
\hline \multirow[t]{2}{*}{3} & Median & $45 \cdot 0$ & $5 \cdot 4$ \\
\hline & Ulnar & $30 \cdot 2$ & $8 \cdot 8$ \\
\hline \multirow[t]{2}{*}{4} & Median & $23 \cdot 2$ & $11 \cdot 2$ \\
\hline & UInar & $25 \cdot 4$ & $11 \cdot 4$ \\
\hline
\end{tabular}

reflect the timing and tension changes of the twitch response. Furthermore, the silent period produced by stimulation at the elbow was approximately $25 \mathrm{msec}$ shorter than that produced by stimulation at the wrist despite the 
increased latency of the twitch response. This suggests that the impulses are carried by slowlyconducting nerve fibres at a rate of about 13 $\mathrm{m} / \mathrm{sec}$ (Table 3 ). This is the rate of conduction of delta (pain and temperature) fibres.

The occurrence of a silent period in the abductor pollicis brevis muscle after stimulation of the ulnar nerve at the wrist, or of the radial nerve, was first noted by Liberson (1962). Stimulation of the sural nerve may produce silent periods in the ipsilateral rectus femoris, gastrocnemius, and tibialis anterior muscles (Morris, Pollock, and Hinchcliffe, 1968). Such findings indicate that the afferent volley produced by electrical stimulation inhibits motoneurones serving adjacent localities in the limb. Inhibition has been demonstrated as a result of electrical rather than physiological stimulation, and the physiological role of the pathways involved is obscure. There is no direct evidence that physiological activity in delta sensory fibres has an inhibitory effect upon regional flexor motoneurones (Matthews, 1972). However, the sensitivity of spinal reflexes is known to be controlled by supraspinal centres (Lundberg, 1967). The silent period is prolonged in patients with Parkinsonism, but returns to normal when the tremor is abolished by levodopa (McLellan, 1972). This facilitation of the silent period reflex raises the possibility that ordinary sensory stimuli in Parkinsonism might have an inhibitory effect upon motoneurone activity, increasing the tendency to synchronization and so contributing to the generation of resting tremor (Simpson, 1966).

The end point of the muscle silent period produced by supramaximal electrical stimulation of a mixed peripheral nerve appears to reflect the activity of an inhibitory spinal reflex system, and gives no indication of spindle activity in the muscle.
I wish to thank the subjects for their cooperation, Professor J. A. Simpson for his advice, and Mr. Harry Leigh for technical assistance. The figures were prepared by the Department of Medical Illustration at the Institute of Neurological Sciences.

\section{REFERENCES}

Dietrichson, P. (1972). The silent period in spastic, rigid, and normal subjects during isotonic and isometric muscle contractions. Acta Neurologica Scandinavica, 47, 183-193.

Herman, R. (1969). Silent period during isometric and isotonic contraction. Archives of Physical Medicine and Rehabilitation, 50, 642-646.

Higgins, D. C., Haidri, N. H., and Wilbourn, A. J. (1971). Muscle silent period in Parkinson's disease. Journal of Neurology, Neurosurgery, and Psychiatry, 34, 508-511.

Higgins, D. C., and Lieberman, J. S. (1968a). The muscle silent period: variability in normal man. Electrocencephalography and Clinical Neurophysiology, 24, 176-182.

Higgins, D. C., and Lieberman, J. S. (1968b). The muscle silent period and spindle function in man. Electroencephalography and Clinical Neurophysiology, 25, 238-243.

Liberson, W. T. (1962). Monosynaptic reflexes and their clinical significance. Electroencephalography and Clinical Neurophysiology, Suppl. 22, 79-89.

Lundberg, A. (1967). The supraspinal control of transmission in spinal reflex pathways. Electroencephalography and Clinical Neurophysiology, Suppl. 25, 35-46.

Matthews, P. B. C. (1964). Muscle spindles and their motor control. Physiological Reviews, 44, 219-288.

Matthews, P. B. C. (1972). Mammalian Muscle Receptors and Their Central Actions, pp. 375-380. Monographs of the Physiological Society No. 23. Edward Arnold: London.

McLellan, D. L. (1972). Levodopa in Parkinsonism: reduction in the electromyographic silent period and its relationship with tremor. Journal of Neurology, Neurosurgery, and Psychiatry, 35, 373-378.

Merton, P. A. (1951). The silent period in a muscle of the human hand. Journal of Physiology, 114, 183-198.

Morris, J. M., Pollock, S. F., and Hinchcliffe, H. A. (1968). Elicitation of Periods of Inhibition in Human Muscle by Stimulation of Cutaneous Nerves: Possible Implications for Alleviation of Spasticity. Biochemics Laboratory, University of California, San Francisco and Berkeley. Technical Report 59.

Simpson, J. A. (1966). Control of muscle in health and disease. In Control and Innervation of Skeletal Muscle, pp. 171-181. Edited by B. L. Andrew. Livingstone: Edinburgh.

Vallbo, A. B. (1970). Discharge patterns in human muscle spindle afferents during isometric voluntary contractions. Acta Physiologica Scandinavica, 80, 552-566. 